\title{
Simulation of airbag impact on eyes with different axial lengths after transsclerally fixated posterior chamber intraocular lens by using finite element analysis
}

\author{
This article was published in the following Dove Press journal: \\ Clinical Ophthalmology \\ 5 February 2015 \\ Number of times this article has been viewed
}

\author{
Jane Huang' \\ Eiichi Uchio' \\ Satoru Goto ${ }^{2}$ \\ 'Department of Ophthalmology, \\ Fukuoka University School of \\ Medicine, Fukuoka, ${ }^{2}$ Nihon ESI KK \\ Technical Division, Tokyo, Japan
}

Correspondence: Jane Huang Department of Ophthalmology, Fukuoka University School of Medicine, 7-45-I Nanakuma, Jonan-ku, Fukuoka 8I4-0180, Japan

Tel +8192801 l0 I I

Fax +8I 928654445

Email janehuang@jcom.home.ne.jp
Purpose: To determine the biomechanical response of an impacting airbag on eyes with different axial lengths with transsclerally fixated posterior chamber intraocular lens (PC IOL).

Materials and methods: Simulations in a model human eye were performed with a computer using a finite element analysis program created by Nihon, ESI Group. The airbag was set to be deployed at five different velocities and to impact on eyes with three different axial lengths. These eyes were set to have transsclerally fixated PC IOL by a 10-0 polypropylene possessing a tensile force limit of $0.16 \mathrm{~N}$ according to the United States Pharmacopeia XXII.

Results: The corneoscleral opening was observed at a speed of $40 \mathrm{~m} / \mathrm{second}$ or more in all model eyes. Eyes with the longest axial length of $25.85 \mathrm{~mm}$ had the greatest extent of deformity at any given impact velocity. The impact force exceeded the tensile force of 10-0 polypropylene at an impact velocity of $60 \mathrm{~m} / \mathrm{second}$ in all eyes, causing breakage of the suture.

Conclusion: Eyes with transsclerally fixated PC IOL could rupture from airbag impact at high velocities. Eyes with long axial lengths experienced a greater deformity upon airbag impact due to a thinner eye wall. Further basic research on the biomechanical response for assessing eye injuries could help in developing a better airbag and in the further understanding of ocular traumas.

Keywords: airbag, ocular trauma, computer simulation, transsclerally fixated posterior chamber intraocular lens, finite element analysis

\section{Introduction}

Airbags have saved thousands of lives since their introduction in the early 1980s. Airbags protect the passengers against a crash by providing a padding device, which allows the impacting and impacted surface to deform, thereby extending the duration of the impact and reducing its severity. ${ }^{1}$ Although airbags have substantially reduced the rate of mortality and morbidity, those who have survived may suffer from various fatal and nonfatal injuries to the head, eyes, neck, chest, or arms. ${ }^{2,3}$ Ocular traumas are among the most severe airbag-induced injuries due to a high risk for detrimental vision impairment after an impact. ${ }^{4}$ Airbag-induced ocular trauma includes corneal abrasion, corneoscleral laceration, subluxated lens, endothelial cell loss, cyclodialysis, choroidal rupture, globe rupture, retinal detachment, and periorbital fracture. ${ }^{5-11}$

Given the initiatives in cataract or corneal surgeries for better vision, an increase in the population achieving the visual acuity test criteria for operating a vehicle would be assumed. ${ }^{4}$ Any driver could be at risk of airbag-induced ocular trauma. In a 1991-1998 
review of 97 patients with airbag-associated eye trauma, 50\% of traumas were limited to the anterior segment, $6 \%$ to the posterior segment, and $44 \%$ to both. ${ }^{12}$ Postcataract surgery patients with implantation of an intraocular lens (IOL) may be at a higher risk with impact for wound rupture, subluxation of a posterior chamber (PC) IOL, anterior capsule rupture, and dislocation of the lens. . $^{1,13,14}$

Unlike with human bones and ribcages, the injury biomechanics of soft organs, such as human eyes, are difficult to simulate due to limited available mechanical information. Cadavers and dummies have been used for research purposes; however, the physiological and biological properties of these eyes do not resemble living eyes, making the trauma research more difficult and results only marginally reliable. Therefore, creating a humanlike eye with raw data from the human eye for biomechanical simulations using finite element analysis (FEA) would help to investigate and better explain the physical and physiological responses to impact injuries. ${ }^{1}$

We have previously developed a simulation model resembling a human eye based on the information obtained from cadaver eyes and applied three-dimensional FEA to determine the physical and mechanical conditions of impacting foreign bodies that cause an intraocular foreign body. ${ }^{15}$ This model human eye was also used in our studies on airbag impact in a postradial keratotomy eye and on a post-transsclerally fixated PC IOL eye. ${ }^{4,16}$ In general, the capsular bag is considered the best position for IOL implantation. When the capsular support is insufficient or absent, ciliary sulcus fixation or, more recently, scleral fixation, is recommended. ${ }^{4}$ In this study, we extended the simulation model after renovation to further determine the physical and mechanical response of an impacting airbag deploying at additional velocities on transsclerally fixated PC IOL eyes with different axial lengths, especially surveying the mechanical threshold in a highly myopic eye.

\section{Materials and methods}

The model human eye was created and used in simulations with a computer using an FEA program, PAM-CRASH (Nihon ESI, Tokyo, Japan), described elsewhere. ${ }^{15}$ The material properties and geometry of the model were obtained from past experiments with three pairs of human cadaver eyes. ${ }^{15}$ Poisson ratios of the cornea at $0.420 \mathrm{~kg} / \mathrm{mm}^{3}$ and the sclera at $0.470 \mathrm{~kg} / \mathrm{mm}^{3}$ were used to determine the standard stress strain curves for the cornea and sclera. ${ }^{17-19}$ The reference point for globe rupture was then calculated to be at a strain of $18.0 \%$ and stress of $9.45 \mathrm{MPa}$ for the cornea, and at a strain of $6.8 \%$ and stress of $9.49 \mathrm{MPa}$ for the sclera. ${ }^{15}$ The cornea was assumed to be spherical, with a central thickness of $0.5 \mathrm{~mm}$ and a central radius of curvature of $7.8 \mathrm{~mm}$. The anterior chamber was set at a depth of $5.1 \mathrm{~mm}$. A transsclerally fixated polymethyl methacrylate PC IOL element was integrated at the original physiological position of the crystal lens. The vitreous length was assumed to be $18.6 \mathrm{~mm}$, and the posterior curvature of the retina was assumed to be $12.0 \mathrm{~mm}$. The mass densities of ocular tissues from past reports were applied as follows: ${ }^{15,20}$ cornea, $1.149 \mathrm{~kg} / \mathrm{mm}^{3}$; sclera, $1.243 \mathrm{~kg} / \mathrm{mm}^{3}$; and vitreous and aqueous humor, $1.002 \mathrm{~kg} / \mathrm{mm}^{3}$ and $1.000 \mathrm{~kg} / \mathrm{mm}^{3}$, respectively. A new approach in this study was the addition of model human eyes with different axial lengths, representing a normal eye with a normal axial length of $23.85 \mathrm{~mm}$, a hyperopic eye with a shorter axial length of $21.85 \mathrm{~mm}$, and a myopic eye with a longer axial length of $25.85 \mathrm{~mm}$. Eyes with different axial lengths were created by setting the mass density of the cornea and sclera as constants, and the element types including the three layers of the model eye (outer, middle, and inner) as variables for meshing principles. ${ }^{15} \mathrm{~A}$ threshold for the thickness reduction ratio was 0.5 (50\%). The elastic properties and meshing principles of the model human eye were similar to those in previous reports. ${ }^{15,16}$ The vitreous model as a solid mass was also assigned with a hydrostatic pressure of $20 \mathrm{mmHg}(2.7 \mathrm{KPa})$. The changes in the deformity of the eye and the strain induced were calculated by the Virtual Performance Solver (VPS) (Nihon ESI KK) and evaluated by color mapping. In this study, mapping properties were renovated for more finite displaying due to the development of computer technology following the previous study. ${ }^{4}$

The simulation of PC IOL implantation was based on a corneoscleral incision size of $6.0 \mathrm{~mm}$ and wound closure with 10-0 polypropylene sutures in five places. A detailed description of a single-piece polymethyl methacrylate IOL and its elasticity and mass density of $2.85 \mathrm{GPa}$ and $1.185 \mathrm{~kg} / \mathrm{mm}^{3}$, respectively, are described elsewhere. ${ }^{4}$ The suturing method was done the same way as reported, with a 10-0 polypropylene looped suture (by an Alcon Surgical PC 91/4 circular needle; Alcon, Inc., Hünenberg, Switzerland) and the loop of each suture was tied with the girth-hitch method. ${ }^{4}$ Two tying needles were placed at the 4 and 10 o'clock positions, and the sutures exited the sclera $1.0 \mathrm{~mm}$ posterior to the limbus and were tied directly to the superficial sclera. The limit of tensile force $(\mathrm{N})$ of a $10-0$ polypropylene suture was specified to be $0.16 \mathrm{~N}$ by the United States Pharmacopeia XXII. ${ }^{21,22}$ Breakage of the fixating suture is assumed to occur in the middle of the suture when the strain becomes intolerable due to deformity of the eye caused by airbag impact. Element deletion was incorporated in the VPS, with rupture of the eye and the breakage of the suture defined as the strain exceeding the corneoscleral and fixation suture threshold, respectively. 
A biomechanical head of a dummy was created, assuming that everything excluding the eye was a solid element, to reduce the computing time. The Hybrid III model was modified ${ }^{4}$ by replacing the head of the dummy with a biomechanical model of the head in which the IOL-fixated model eye was inserted. ${ }^{4,23}$ For simplification of calculation, the angular momentum of the impact missile was ignored in this study. The impact missile for the airbag simulation was set up as described. ${ }^{15}$ The impact missile was a decahedron that was composed of a cuspidal hexahedron and a rectangular parallelepiped, so as to be blunt in shape. ${ }^{15}$ In addition to our previous study, the airbag was deployed at five different velocities (20 $\mathrm{m} / \mathrm{second}, 30 \mathrm{~m} / \mathrm{second}, 40 \mathrm{~m} / \mathrm{second}, 50 \mathrm{~m} / \mathrm{second}$, and $60 \mathrm{~m} /$ second) and it impacted eyes of three different axial lengths.

The simulation program was similar to that of a previous report by Digital Equipment Corporation AlphaStation ${ }^{4}$ using the FEA program, Pam-Crash version 1998 (Nihon ESI KK). ${ }^{4}$ Similarly, suture strain was recorded sequentially in all velocities and the deformity of the eye was displayed sequentially in milliseconds in slow motion. Breakage of the suture was defined as the point when the strain exceeded the tensile tolerance.

\section{Results}

The postoperative PC IOL model human eye with an axial length of $23.85 \mathrm{~mm}$ created by the VPS is shown in Figure 1. The skull surrounding the eye was assumed to be a solid element to minimize the computing time for impact simulation (Figure 2). The thickness of the eye wall depicted by the color maps showed correlation with the axial lengths of the eyes (Figure 3). The eye with a longer axial length is shown in orange, representing a thinner eye wall compared to eyes with normal and shorter axial lengths in red.
The deformity of the three eyes with transsclerally sutured IOL at five impact velocities $(20 \mathrm{~m} /$ second, $30 \mathrm{~m} / \mathrm{second}$, $40 \mathrm{~m} / \mathrm{second}, 50 \mathrm{~m} / \mathrm{second}$, and $60 \mathrm{~m} /$ second) is captured in slow motion (shown in Figures 4A, 5A, and 6A). Corneoscleral deformity was observed after $0.1 \sim 0.2 \mathrm{~ms}$ of impact in all velocities. The deformity of the eye was small at 20 $\mathrm{m} /$ second and $30 \mathrm{~m} / \mathrm{second}$. Deformity reached the threshold of corneoscleral strain $(0.068)$ at $40 \mathrm{~m} / \mathrm{second}, 50 \mathrm{~m} / \mathrm{second}$, and $60 \mathrm{~m} / \mathrm{second}$, causing the model eye to rupture. The tensile force on the 10-0 polypropylene suture of the three eyes is shown in Figures 4B, 5B, and 6B. At $0.3 \mathrm{~ms}$ after the impact, the eye with the longest axial length had the greatest extent of deformity at any given impact velocity (Figure 7).

The tensile force on the suture exceeded the critical value at only the velocity of $60 \mathrm{~m} / \mathrm{second}$ in all eyes. This breakage of the suture occurred in all eyes after $0.3 \mathrm{~ms}$ impact, with the longest axial length exceeding the breaking force initially between $0.2 \mathrm{~ms}$ and $0.3 \mathrm{~ms}$. There was no breakage of the scleral fixation suture at $40 \mathrm{~m} / \mathrm{second}$ and $50 \mathrm{~m} /$ second, even when the force on the corneoscleral incision suture was continuously greater with increasing velocity. At $60 \mathrm{~m} / \mathrm{second}$ impact, the suture tensile force was exceeded at the sites of the scleral fixation suture, leading to both ocular rupture and breakage of the suture (Figures 4B, 5B, and 6B).

\section{Discussion}

In a frontal crash automobile accident, drivers move forward rapidly and may be struck forcefully by a rearward-expanding bag at high velocities, causing the impacted eye to deform. ${ }^{1,12}$ Despite its overall protective effects, this forceful inflation of the airbag itself could be the major contributor of ocular injuries, even in minor accidents such as bumper-to-bumper contact or even a flat tire. ${ }^{14}$ According to the US Federal Motor
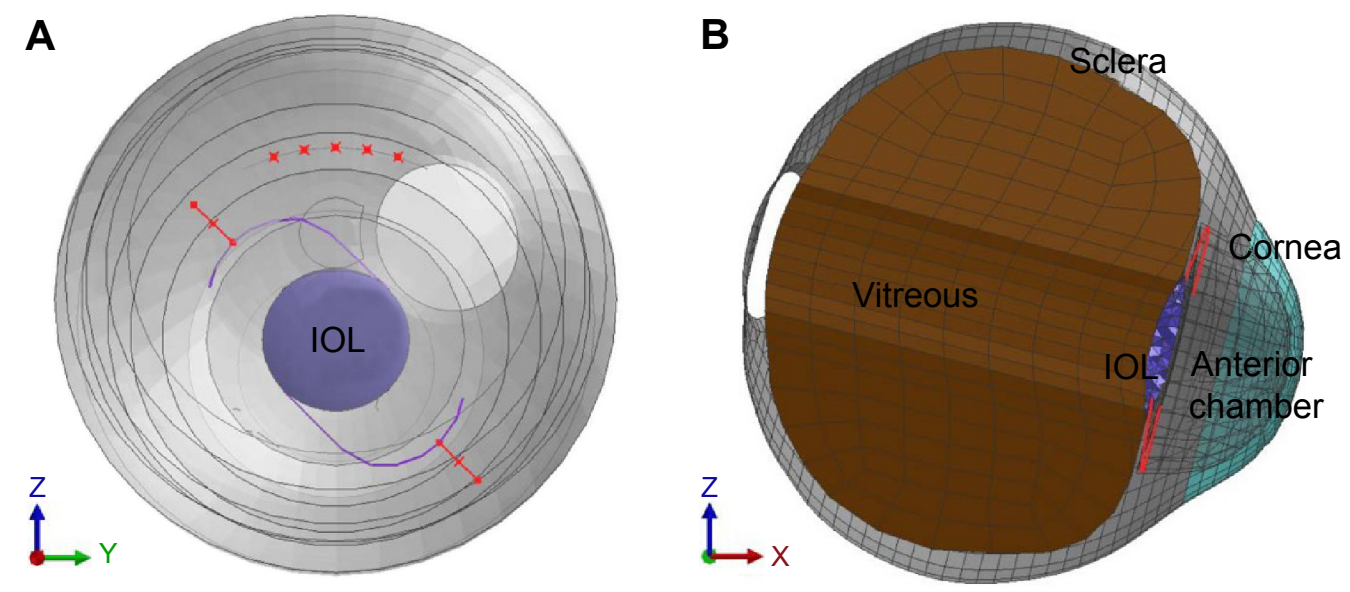

Figure I Frontal view of the model eye with transsclerally fixated PC IOL.

Notes: (A) Four and 10 o'clock positions; Cornealscleral incision site for IOL insertion at the 12 o'clock position (B) sagittal view of the model eye. Abbreviations: IOL, intraocular lens; PC, posterior chamber. 


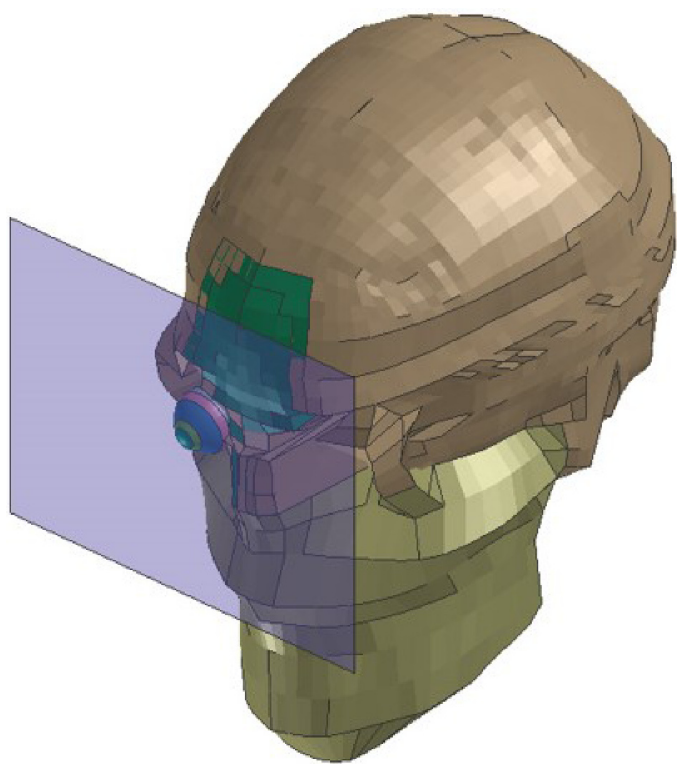

Figure 2 A biomechanical model of the head.

Notes: Parts other than the eye were assumed to be solid elements, and the impact object was placed adjacent to the eyeball to reduce the computing time of the airbag impact simulation.

Vehicle Safety Standards, airbags take only $20 \mathrm{~m} / \mathrm{second}$ to fully inflate, which is about four times faster than blinking. ${ }^{25}$ Airbag deployment occurs $15 \mathrm{~ms}$ after an impact with complete expansion at $50 \mathrm{~ms}$ and deflation by $100 \mathrm{~ms} .{ }^{8}$ Automobile airbags are reported to deploy at a speed ranging from 81-322 kph (22-89 m/seconds). ${ }^{8,25-27}$ Considering that some

\section{Normal}

$23.85 \mathrm{~mm}$

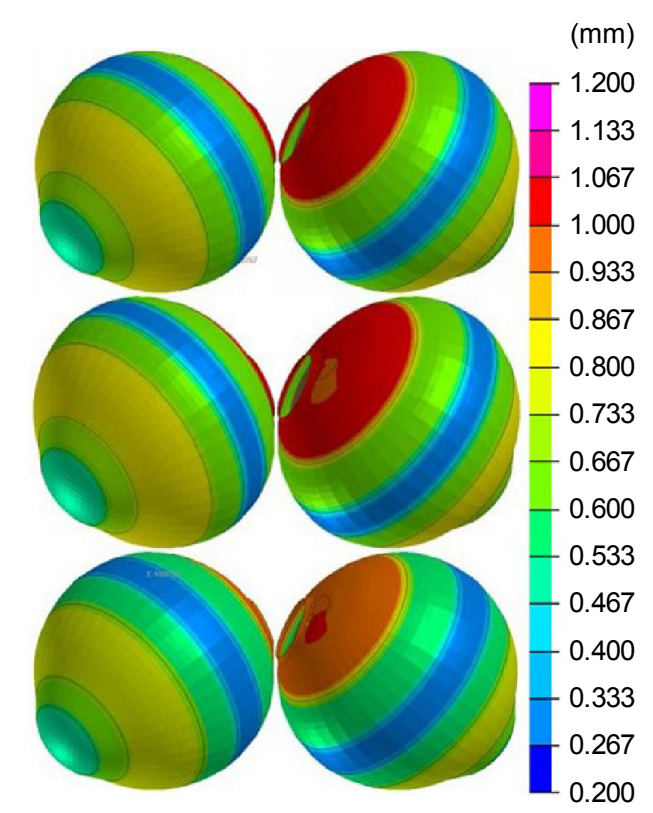

Figure 3 The thickness of the eye wall $(\mathrm{mm})$ is depicted from cold to warm colors.

Notes: A warmer color of red represents a thicker eye wall; a myopic eye with a longer axis shows a thinner eye wall. situations exceeded the impact velocities in the previous report, ${ }^{4}$ we added $50 \mathrm{~m} / \mathrm{second}$ and $60 \mathrm{~m} / \mathrm{second}$ velocities to this study. From our results, ocular rupture and breakage of the sutures occurred at $60 \mathrm{~m} / \mathrm{second}$. Therefore, no further velocities were performed for the simulation. Since eyeballs are viscoelastic, their response to impact injury is rate sensitive. ${ }^{1}$ Therefore, we simulated the impacts of various velocities within the range of speed of deployment in this study to see the biomechanical response for different axial lengths. Our present study demonstrated that eyes remained intact up to a $30 \mathrm{~m} / \mathrm{second}$ impact speed. Corneoscleral opening occurred at $40 \mathrm{~m} / \mathrm{second}, 50 \mathrm{~m} / \mathrm{second}$, and $60 \mathrm{~m} / \mathrm{second}$, and eventually the ocular and fixation suture ruptured at $60 \mathrm{~m} / \mathrm{second}$. The results suggested that ocular rupture and fixating suture breakage could happen even at mid-speed of airbag deployment. Furthermore, at the fastest velocity of $60 \mathrm{~m} / \mathrm{second}$, corneoscleral rupture was observed as early as $0.1 \sim 0.2 \mathrm{~ms}$ after the airbag impact, suggesting that all eyes regardless of axial length would be vulnerable to a higher speed of impact.

In the era of refractive surgeries, the effect on the ocular integrity of cataract surgical techniques may depend on the physical properties of the eye. To our knowledge, no published data on the mechanical properties, especially on the tensile strength, of the zonule of Zinn, which is essential for the simulation of airbag impact on a phakic or a pseudophakic eye, are available. Transsclerally fixating the PC IOL with a 10-0 polypropylene suture is still the most widely performed method for complicated eyes without capsular support. In contrast, since the tensile strain of the polypropylene suture is available from the manufacturer, the simulation of airbag impact on the transsclerally-IOL-sutured eye can be established by modification of our previous simulation model. ${ }^{4}$ We have already demonstrated and assessed the mechanical properties of an eye with a transsclerally fixated PC IOL in a past report showing IOL subluxation with an impact velocity of $40 \mathrm{~m} /$ second. $^{4}$ However, individual variations regarding axial lengths, age, or ethnicity were not considered in previous studies. ${ }^{4}$ Then, we carried out the current simulated study using the PC IOL transsclerally fixing model with several modifications.

It is known that there has been a global increase in the prevalence of myopia over the past half-century, particularly in affluent, industrialized areas of East Asia. ${ }^{24}$ Higher myopia, which means a longer axial length, is associated with comorbidities that increase the risks of severe and irreversible loss of vision, such as retinal detachment, subretinal neovascularization, dense cataract, and glaucoma. ${ }^{24}$ Therefore, longer eyes with thinner walls would be much more vulnerable to any kind of impact trauma. This study demonstrated that these eyes with a longer 


\section{A Normal axial length $(23.85 \mathrm{~mm})$}
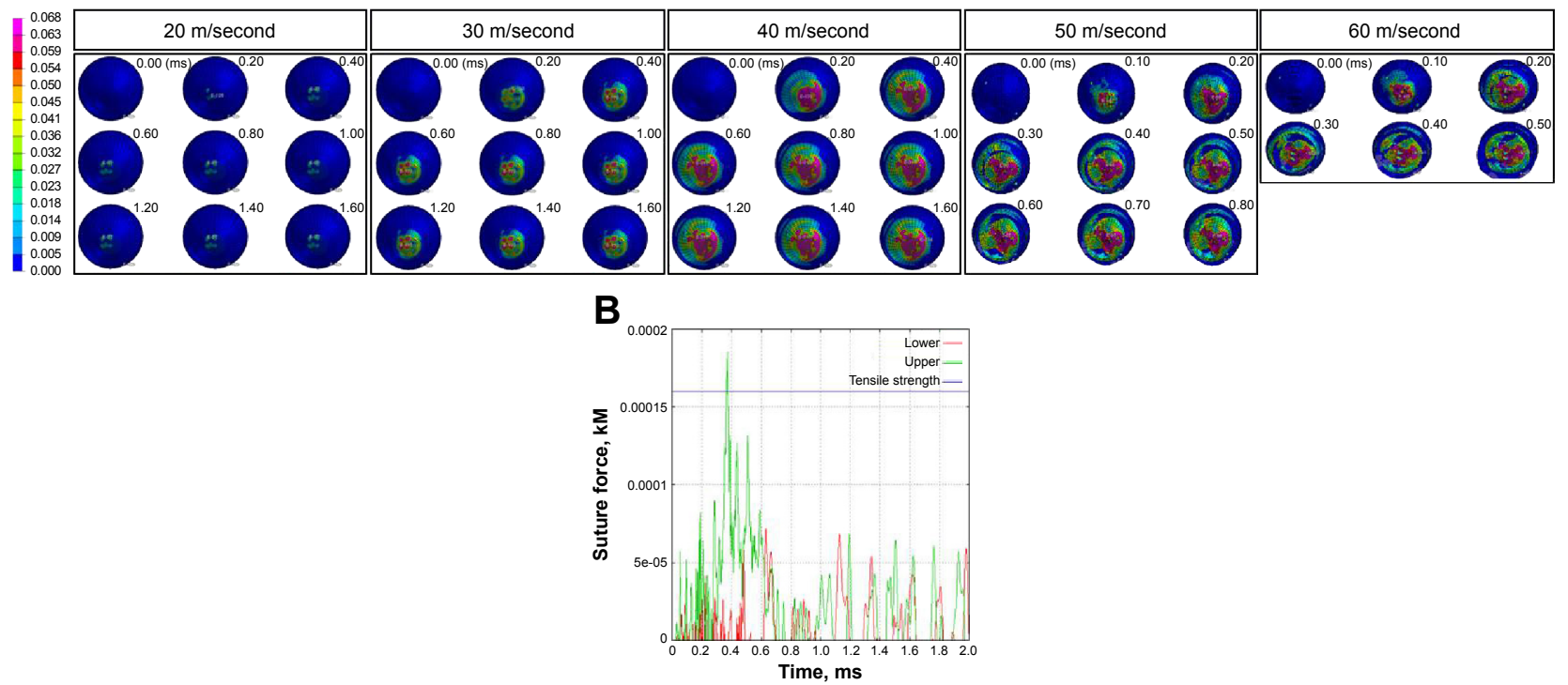

Figure 4 Sequential deformity of a normal axial length model eye upon airbag impact at five different velocities, shown in ms intervals.

Notes: (A) The deformity became irreversible, suggesting a corneoscleral rupture at $0.3 \mathrm{~ms}$ after impact velocities over $40 \mathrm{~m} / \mathrm{second}$, shown in hot pink. (B) The tensile force of the 10-0 polypropylene suture was exceeded only at an impact velocity of $60 \mathrm{~m} / \mathrm{second}$ after $0.3 \mathrm{~ms}$, suggesting fixation suture breakage (lower: 4 o'clock fixation suture; upper: 10 o'clock fixation suture).

axial length are prone to a more extensive ocular deformity, causing irreversible strain on the eye, leading to ocular and fixation suture rupture if present. Longer eyes showed breakage of the fixation suture as early as $0.1 \mathrm{~ms}$ after the airbag impact.

Other possible factors affecting the integrity of the driver's eye upon airbag impact would be age, sex, weight, usage of spectacles, and ethnicity. ${ }^{2}$ Some data indicated that women of small stature and shallower eye sockets, common in Asians, are more likely to be injured by airbag impacts because they are likely to sit too close to the wheel, which could cause fatal or nonfatal injuries when the airbag is deployed. ${ }^{2,3}$ Elderly women with smaller statures would be physiologically characterized with normal or smaller eye axial lengths. ${ }^{3}$ This physiological factor would make this population at high

\section{A Long axial length $=$ myopic $(25.85 \mathrm{~mm})$}
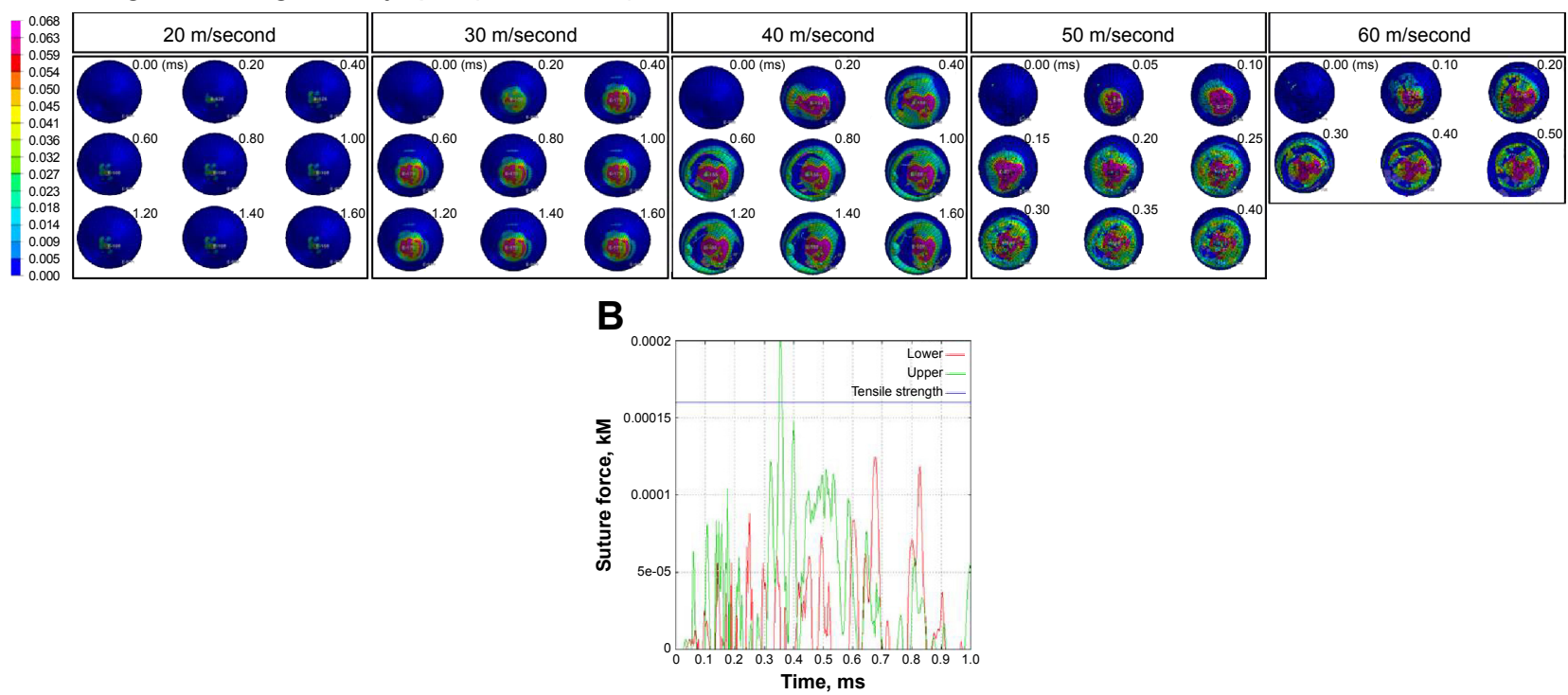

Figure 5 Sequential deformity of a long axial length (myopic) model eye upon airbag impact at five different velocities, shown in ms intervals.

Notes: (A) Deformity became irreversible at $0.3 \mathrm{~ms}$ after impact velocities over $40 \mathrm{~m} / \mathrm{second}$, shown in hot pink. (B) The tensile force of the I0-0 polypropylene suture was exceeded only at an impact velocity of $60 \mathrm{~m} / \mathrm{second}$ after $0.3 \mathrm{~ms}$, suggesting fixation suture breakage (lower: 4 o'clock fixation suture; upper: 10 o'clock fixation suture). 


\section{A Short axial length $=$ hyperopic $(21.85 \mathrm{~mm})$}

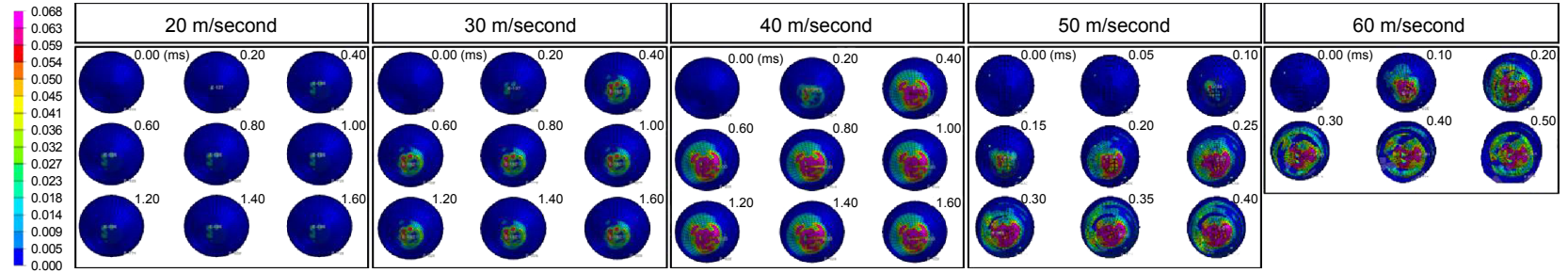

B

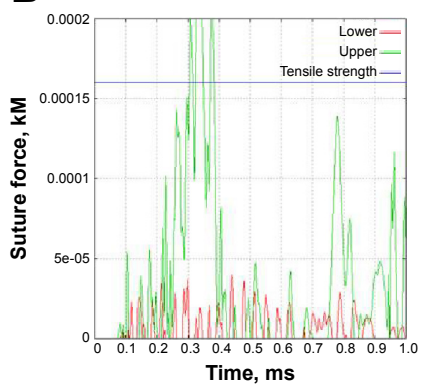

Figure 6 Sequential deformity of a short axial length (hyperopic) model eye upon airbag impact at five different velocities, shown in ms intervals.

Notes: (A) Deformity became irreversible at $0.3 \mathrm{~ms}$ after impact velocities over $40 \mathrm{~m} / \mathrm{second}$, shown in hot pink. (B) The tensile force of the $10-0$ polypropylene suture was exceeded only at an impact velocity of $60 \mathrm{~m} / \mathrm{second}$ after $0.3 \mathrm{~ms}$, suggesting fixation suture breakage (lower: 4 o'clock fixation suture; upper: 10 o'clock fixation suture).

risk for blunt ocular injuries. Our data showed that even at the medium velocity of $30 \mathrm{~m} / \mathrm{second}$, corneoscleral incisions and IOL would be at risk in normal to shorter axial length eyes. Sitting closer to the steering wheel would decrease the distance to the driver's face and, therefore, increase the impact velocity and its force on these individuals.

Studies of the wound upon blunt airbag impact are of interest to ophthalmologists. The study of trauma could provide insights on how the eye responds to impact injury, and would thus help to establish preventative surgical measures such as revising the surgical wound, performing IOL fixation methods, improving suture material, or inserting IOL implants. At the same time, blunt airbag impact studies could also help automobile industries make more adaptable airbags customized for different ethnic backgrounds and physical characteristics.

Despite our careful calculation of the simulation model based on cadaver eyes, there are still limitations to our study. ${ }^{15}$ First, since studies are based on only three pairs of cadaver eyes, the results do not completely resemble a living humanlike eye response, or represent the normal population. Second, in order to reduce the time for computer calculation, the impact object was placed almost adjacent to the surface

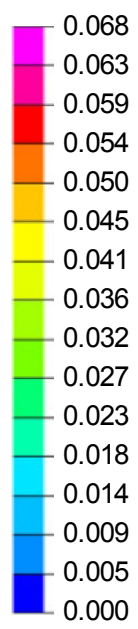

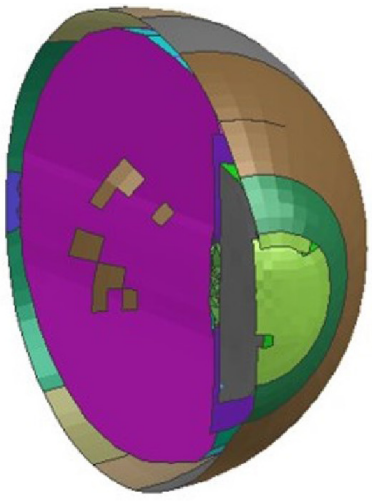

Normal $(23.85 \mathrm{~mm})$

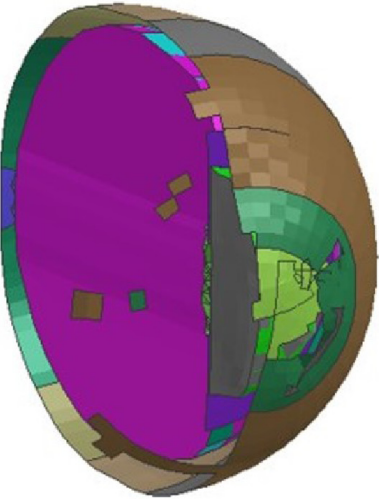

Myopic (25.85 mm)

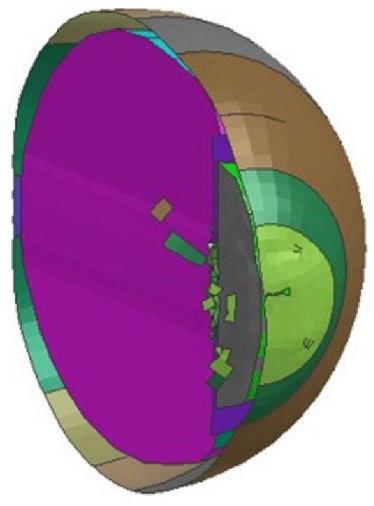

Hyperopic $(21.85 \mathrm{~mm})$

Figure 7 Sagittal view of the model eye at $0.3 \mathrm{~ms}$ after the airbag impact.

Notes: The myopic eye, the eye with the longest axial length of $25.85 \mathrm{~mm}$, showed the most corneoscleral deformity, with multiple color spots on the anterior portion of the model eye. 
of the eyeball for the impact simulation. Therefore, further study on the distance of the deploying airbag to the driver in regard to the change in velocity would be necessary to determine the extent of impact that is likely to happen in real situations. Finally, the vitreous model was a solid mass with a physiological intraocular pressure of $20 \mathrm{mmHg} .{ }^{15}$ The age factor for vitreous viscosity or other physical characteristics were not taken into account as variables in our simulation. However, we believe that our goal to assess the mechanical properties of eyes with different axial lengths with a fixated IOL suture was achieved by demonstrating that the corneoscleral incision would open at a medium velocity followed by IOL subluxation, with the eye with the longest axial length being more susceptible to impact injuries. Furthermore, at a maximum velocity of $60 \mathrm{~m} / \mathrm{second}$, the impact force exceeded the fixated suture force, causing suture breakage.

\section{Conclusion}

In conclusion, even with improvements in automobile industry technology, there is still need for the conscientious reporting of vision-threatening airbag impact injuries. The lack of basic research data on the biomechanical response has retarded the development of more sophisticated models or dummies. Therefore, this current method of injury biomechanics research for assessing eye injuries would help advance our knowledge on the mechanism of ocular traumas and reduce the need for animal experiments and cadavers, which are difficult to obtain and could pose ethical issues. Finally, an ability to predict anatomical or structural injury upon airbag impact would be critical to safety. Continuous injury biomechanics research would be helpful not only in developing an adequate evaluation system for airbag safety, but also in further understanding ocular preventative measures. These may include the use of protective goggles, the revision of PC IOL fixations sutures, minimal surgical incisions, or placing the PC IOL without sutures.

\section{Acknowledgment}

We thank Mr Tony Yang for editing this manuscript.

\section{Disclosure}

The authors report no conflicts of interest in this work.

\section{References}

1. Viano DC, King AI, Melvin JW, Weber K. Injury biomechanics research: an essential element in the prevention of trauma. J Biomech. 1989; 22(5):403-417.

2. Segui-GomezM,LevyJ, RomanH, Thompson KM, McCabe K, GrahamJD. Driver distance from the steering wheel: perception and objective measurement. Am J Public Health. 1999;89(7):1109-1111.
3. Manche EE, Goldberg RA, Mondino BJ. Air bag-related ocular injuries. Ophthalmic Surg Lasers. 1997;28(3):246-250.

4. Uchio E, Kadonosono K, Matsuoka Y, Goto S. Simulation of air-bag impact on an eye with transsclerally fixated posterior chamber intraocular lens using finite element analysis. J Cataract Refract Surg. 2004; 30(2):483-490.

5. de Vries S, Geerards AJ. Long-term sequelae of isolated chemical "airbag" keratitis. Cornea. 2007;26(8):998-999.

6. Baker RS, Flowers CW, Singh P, Smith A, Casey R. Corneoscleral laceration caused by air-bag trauma. Am J Ophthalmol. 1996;121(6):709-711.

7. Scott IU, Greenfield DS, Parrish RK. Airbag-associated injury producing cyclodialysis cleft and ocular hypotony. Ophthalmic Surg Lasers. 1996;27(11):955-957.

8. Fukagawa K, Tsubota K, Kimura C, et al. Corneal endothelial cell loss induced by air bags. Ophthalmology. 1993;100(12):1819-1823.

9. Han DP. Retinal detachment caused by air bag injury. Arch Ophthalmol. 1993;111(10):1317-1318.

10. Scott IU, John GR, Stark WJ. Airbag-associated ocular injury and periorbital fractures. Arch Ophthalmol. 1993;111(1):25.

11. Vichnin MC, Jaeger EA, Gault JA, Jeffers JB. Ocular injuries related to air bag inflation. Ophthalmic Surg Lasers. 1995;26(6):542-548.

12. Almahmoud T, Barss P. Vehicle occupant restraint systems impact on eye injuries: a review. Surv Ophthalmol. 2014;59(3):334-344.

13. Onwuzuruigbo CJ, Fulda GJ, Larned D, Hailstone D. Traumatic blindness after airbag deployment: bilateral lenticular dislocation. J Trauma. 1996;40(2):314-316.

14. Ghafouri A, Burgess SK, Hrdlicka ZK, Zagelbaum BM. Air bag-related ocular trauma. Am J Emerg Med. 1997;15(4):389-392.

15. Uchio E, Ohno S, Kudoh J, Aoki K, Kisielewicz LT. Simulation model of an eyeball based on finite element analysis on a supercomputer. Br J Ophthalmol. 1999;83(10):1106-1111.

16. Uchio E, Ohno S, Kudoh K, Kadonosono K, Andoh K, Kisielewicz LT. Simulation of air-bag impact on post-radial keratotomy eye using finite element analysis. J Cataract Refract Surg. 2001;27(11):1847-1853.

17. Buzard KA. Introduction to biomechanics of the cornea. Refract Corneal Surg. 1992;8(2):127-138.

18. Greene PR. Closed-form ametropic pressure-volume and ocular rigidity solutions. Am J Optom Physiol Opt. 1985;62(12):870-878.

19. Hoeltzel DA, Altman P, Buzard K, Choe K. Strip extensiometry for comparison of the mechanical response of bovine, rabbit, and human corneas. J Biomech Eng. 1992;114(2):202-215.

20. Reichel E, Miller D, Blanco E, Mastanduno R. The elastic modulus of central and perilimbal bovine cornea. Ann Ophthalmol. 1989;21(6): 205-208.

21. United States Pharmacopeial Convention. Webpage on Internet. The United States Pharmacopeia. The National Formulary, 22nd Revision, Rockville, MD, USA, 1990.

22. Whitley JQ, Prewitt MJ, Kusy RP. Relationship of the diameter and tensile strength of nylon sutures to the USP specification and the effect of preconditioning. J Appl Biomater. 1990;1(4):315-320.

23. Ruan JS, Prasad P. Coupling of a finite element human head model with a lumped parameter Hybrid III dummy model: preliminary results. J Neurotrauma. 1995;12(4):725-734.

24. Foster PJ, Jiang Y. Epidemiology of myopia. Eye (Lond). 2014;28(2): 202-208.

25. National Highway Traffic Safety Administration. Air Bag Deployment Characteristics. Springfield, VA: National Technical Information Service; 1992

26. Schreck RM, Rouhana SW, Santrock J, et al. Physical and chemical characterization of airbag effluents. J Trauma. 1995;38(4):528-532.

27. Ball DC, Bouchard CS. Ocular morbidity associated with airbag deployment: a report of seven cases and a review of the literature. Cornea. 2001;20(2):159-163. 


\section{Publish your work in this journal}

Clinical Ophthalmology is an international, peer-reviewed journal covering all subspecialties within ophthalmology. Key topics include: Optometry; Visual science; Pharmacology and drug therapy in eye diseases; Basic Sciences; Primary and Secondary eye care; Patient Safety and Quality of Care Improvements. This journal is indexed on

Submit your manuscript here: http://www.dovepress.com/clinical-ophthalmology-journal
PubMed Central and CAS, and is the official journal of The Society of Clinical Ophthalmology (SCO). The manuscript management system is completely online and includes a very quick and fair peer-review system, which is all easy to use. Visit http://www.dovepress.com/ testimonials.php to read real quotes from published authors. 